\title{
Cancer/Testis Antigen Family 45 Member
} A2

National Cancer Institute

\section{Source}

National Cancer Institute. Cancer/Testis Antigen Family 45 Member A2. NCI Thesaurus. Code C126601.

Cancer/testis antigen family 45 member A2 (189 aa, $21 \mathrm{kDa}$ ) is encoded by the human CT 45A2 gene. This protein may be involved in tumorigenesis and testis development. 